\title{
GEOPOLÍTICA DA PANDEMIA, ESCALAS DA CRISE E CENÁRIOS EM DISPUTA ${ }^{12}$
}

Pandemic geopolitics, scales of the crisis and disputed scenarios

BRINGEL, Breno 3

Resumo: Este artigo analisa a geopolítica da pandemia de COVID-19 a partir de três eixos interrelacionados que permitem observar as respostas e recomposições do poder e das resistências: condicionantes geopolíticos, representações geopolíticas e cenários póspandemia. No primeiro caso, discutem-se criticamente os antecedentes e as causas da pandemia, a partir de diferentes coordenadas espaço-temporais, localizando-a no bojo de uma crise civilizatória mais ampla e dos limites ecossistêmicos. No segundo, propõe-se um quadro de reorganização espacial com representações geopolíticas que enfatizam o caos global, a fragilidade política de blocos regionais e a centralidade adquirida pela ação estatal e as iniciativas locais com enraizamento comunitário e territorial. Por fim, são desenhados três cenários pós-pandemia em disputa: o da "recuperação", baseado na lógica do "business as usual" e do crescimento econômico; o da "adaptação", com propostas de reformas do capitalismo diante da emergência climática; e, finalmente, o da mudança de paradigma rumo a uma nova matriz ecosocial, orientada pelo anti-capitalismo e pela justiça ambiental e social.

Palavras-chave: pandemia da COVID-19; crise ambiental; representações geopolíticas; caos global; cenários pós-pandemia

\begin{abstract}
This article analyzes the geopolitics of the COVID-19 pandemic from three interrelated axes that allow us to observe the responses and recompositions of power and resistances: geopolitical constraints, geopolitical representations and post-pandemic scenarios. In the first case, the antecedents and causes of the pandemic are discussed, based on different spatio-temporal dimensions, framing it within a broader civilizational crisis and ecosystem limits. In the second, a picture of spatial reorganization is drawn with geopolitical representations that highlight global chaos, the political fragility of regional blocks and the centrality acquired by state action and local initiatives with community and territorial roots. Finally, three post-pandemic contentious scenarios are drawn: that of "recovery", based on the logic of business as usual and economic growth; that of "adaptation", with proposals for capitalist reforms in the face of the climate emergency; and, finally, the paradigm shift towards a new ecosocial matrix, guided by anti-capitalism, and environmental and social justice.
\end{abstract}

Keywords: COVID-19 pandemic; environmental crisis; geopolitical representations; global chaos; post-pandemic scenarios.

\footnotetext{
${ }^{1}$ Este artigo foi originalmente publicado em espanhol em Geopolítica(s). Revista de Estudios Sobre Espacio y Poder, 11(Especial), 173-187, 2020. Tradução de Vitória González Rodríguez.

2 Recebido em: 15 Ago. 2020. | Aceito em: 15 Set. 2020.

3 Professor titular de Sociologia do Instituto de Estudos Sociais e Políticos da Universidade do Estado do Rio de Janeiro (IESP-UERJ) e Pesquisador do Conselho Brasileiro de Pesquisa (CNPq). https://uerj.academia.edu/BrenoBringel
} 


\section{Introdução 4}

Quando o novo coronavírus SARS-CoV-2, causador da doença Covid-19, foi descoberto na cidade chinesa de Wuhan em dezembro de 2019, a reação da grande maioria dos países foi minimizá-lo. Enquanto isso, em várias partes do mundo, proliferavam episódios de sinofobia. Além do racismo e da xenofobia, fortalecidos por um crescente autoritarismo social e político, o "não é com a gente se não nos afeta" não só reflete uma posição antissolidária e pouco empática por parte dos Estados, como também ilustra como se desdenhou uma perspectiva preventiva, por mais que, nas últimas três décadas, os especialistas em saúde pública tenham identificado uma série de infecções e doenças respiratórias emergentes que poderiam ter implicações desastrosas (Ramonet, 2020). De fato, desde a virada do século, organizações multilaterais e internacionais, empresários, relatórios de inteligência e redes científicas insistentemente alertaram Estados e líderes políticos sobre a necessidade urgente de nos prepararmos para mitigar os efeitos de uma possível pandemia (Fidler, 2020).

Por sua vez, lutas comunitárias-territoriais e movimentos sociais, principalmente os ecologistas e indígenas, há várias décadas denunciam que os desequilíbrios ecossistêmicos - causados por um modelo destrutivo de desenvolvimento baseado no crescimento econômico permanente, na velocidade da globalização capitalista e no consumo desenfreado - nos levariam não apenas a uma deterioração global que implicaria muitos riscos à saúde e à vida, mas também a uma rota acelerada rumo ao colapso (Herrero, 2006). A grande diferença é que, enquanto o grito ecologista advertia que o antropocentrismo e o capitalismo eram incompatíveis com a saúde e com a sustentabilidade do planeta, as vozes institucionais e empresariais levantavam um alerta

\footnotetext{
${ }^{4}$ Agradeço a Enara Echart pelas conversas de quarentena e a Heriberto Cairo, José Maurício Domingues, Teivo Teivainen e Franck Tavares pelos comentários. Aos/às pesquisadores/as do Núcleo de Estudos de Teoria Social e América Latina (NETSAL) do IESP UERJ pelas conversas (virtuais, é claro) sobre a política em tempos de coronavírus. Meus agradecimentos também aos/às companheiros/as do Grupo Permanente de Alternativas ao Desenvolvimento, promovido pela Fundação Rosa Luxemburgo, pelas discussões recentes, bem como a Arturo Escobar, Kathya Araujo, Montserrat Sagot, Paula Irene Villa, Paulo Henrique Martins, Pablo Vommaro e Geoffrey Pleyers pelo debates na mesa redonda "Coronavírus e disputas pelo público e pelo comum na América Latina”, organizada pela Associação Latino-Americana de Sociologia (ALAS), pelo Conselho Latino-Americano de Ciências Sociais (CLACSO) e pela International Sociological Association (ISA), em 15 abril de 2020. De lá surgiram as provocações iniciais que levaram ao presente artigo.
} 
para salvar não só vidas humanas, mas principalmente o capitalismo, tratando de evitar grandes perdas econômicas.

Previsões (e falhas de prevenção) à parte, a pandemia do coronavírus expandiuse em nosso mundo acelerado e interconectado com uma rapidez incrível, transbordando a todos e convertendo-se em um evento histórico único. Embora tenha havido muitas outras pandemias na história, nenhuma é igual às demais e elas se dão em cenários societais e geopolíticos diferentes. Em outras palavras, a pandemia do coronavírus não chega em um espaço-tempo qualquer. Chega em um momento histórico de esgotamento dos recursos naturais e de emergência climática e ambiental. Também de retrocessos democráticos e em direitos, bem como de desconfiança e rejeição dos sistemas políticos. Da mesma forma, vivemos em sociedades fendidas por profundas desigualdades (não apenas Norte/Sul, senão dentro das sociedades nacionais) e com os serviços públicos desmantelados por décadas de neoliberalismo que, além da economia, também impregnaram fortemente as subjetividades individuais e coletivas. Enquanto isso, a digitalização da sociedade possibilitou uma maior interação entre as pessoas e um maior fluxo de informações sobre a pandemia, mas isso esteve acompanhado, antes e além do coronavírus, por um processo de crescente individualização, circulação de boatos e geração de dispositivos de vigilância e controle social.

Se, na memória coletiva ocidental, há mais rastros da crise financeira de 2008 e suas sequelas sociais do que de pandemias recentes, o mesmo não ocorre no caso dos continentes asiático e africano, levando em consideração as fortes reminiscências da Síndrome Respiratória Aguda Grave (SARS) e de Ebola, respectivamente. Os números de contágios e mortes, contabilizados ou não, oscilam muito de acordo com cada lugar, mas também variam as condições materiais e as percepções e práticas sociais da população para enfrentar a crise. 0 sociólogo moçambicano Elisio Macamo argumenta que boa parte da resposta dos países europeus à pandemia do coronavírus é informada por uma visão muito local da noção de "risco" (Macamo, 2020). Segundo este mesmo autor, as respostas europeias baseiam-se em uma noção de risco derivada das condições particulares pelas quais as sociedades tecnologicamente avançadas tornaram-se vulneráveis devido ao seu próprio "progresso".

Existe, consequentemente, um imaginário geopolítico colonial e eurocêntrico sobre a "normalidade" e o "risco". É necessário lembrar que a "normalidade" de alguns 
implicou sempre a "crise" de outros. A "segurança" de alguns não existiria sem a "insegurança" de outros. Ou, como a teoria da dependência insistiu, o "desenvolvimento" de alguns significa, invariavelmente, o "subdesenvolvimento" de outros. Sob este guarda-chuva, o risco na Europa e no Ocidente como um todo construiu-se sob uma illusio elitista e restrita que protege alguns enquanto exclui outros.

A crise associada à pandemia tornou-se "global" não apenas porque o vírus viajou por todo o mundo, mas também por certa prepotência nas representações geopolíticas ocidentais. Ao afetar completamente a Europa e os Estados Unidos, é verdade que parte de sua população viveu pela primeira vez em sua própria pele restrições, temores e medos que apenas as pessoas com idade mais avançada (tão maltratadas pela pandemia) dessas sociedades haviam experimentado em momentos históricos anteriores. No entanto, nesta equação costuma-se omitir que grupos marginalizados e excluídos no próprio centro do sistema-mundo ou as maiorias sociais do resto do mundo já estão acostumados a viver sob ameaças constantes, em doses inclusive muito mais fortes e por causas, frequentemente, mais facilmente evitáveis. Também é verdade, por outro lado, que a crise sanitária nos Estados Unidos e na Europa levou à proliferação de várias iniciativas de apoio mútuo, cuidado coletivo e redes solidárias. Porém, em boa parte da África, as redes comunitárias e a "família extensa" são a maior garantia para sustentar a vida sempre - e não apenas em períodos de exceção. Da mesma forma, enquanto no Ocidente continua existindo uma visão da saúde como uma questão individual e fisiológica que se trata em hospitais, em várias localidades da América Latina cultiva-se e pratica a saúde coletiva e comunitária, com todas as suas dificuldades e potencialidades.

Desta forma, as relações históricas entre espaço, poder e resistências, bem como as fissuras de classe, gênero e raça, são fundamentais para entender os condicionantes geopolíticos da pandemia e de sua gestão, bem como as representações geopolíticas da pandemia. Mas independentemente das posições sociais e sistêmicas, a pandemia do coronavírus fez o tabuleiro geopolítico tremer. Desde o início, se difundiram dezenas de hipóteses sobre os cenários do mundo vindouro, mas todas elas ainda são muito provisórias. Não é apenas difícil, mas prepotente tratar de definir cenários bem estabelecidos de futuro (Segato, 2020), no entanto, ao mesmo tempo, é importante reconhecer certas tendências e projetá-las em uma historicidade mais ampla. Neste 
sentido, deve-se reconhecer que os impactos geopolíticos da pandemia serão brutais, embora nem todas as mudanças que vive(re)mos derivem da pandemia em si, senão são exacerbadas por ela.

Entre as principais questões emergentes estão as dinâmicas e os mecanismos de reestruturação do poder global; a governança global e a dimensão espacial da crise sanitária; o fechamento de fronteiras e suas implicações humanitárias, geoeconômicas e na gestão da pandemia; os modelos societais e econômicos para sair da crise e suas implicações sócio-territoriais; as estratégias das coletividades dominantes para seguir dinamizando a acumulação capitalista; as narrativas e os discursos geopolíticos em disputa sobre o coronavírus e o mundo pós-pandemia; e o futuro do papel do Estado e do sistema interestatal. Boa parte das análises geopolíticas sobre a pandemia dedica-se a um ou outro desses aspectos. No entanto, uma geopolítica crítica, além de analisar como o poder opera, também precisa examinar as práticas, discursos e imaginários geopolíticos que emergem como forma de resistir no curto prazo ou de tecer outros mundos possíveis no futuro próximo.

Frente a este complexo cenário e aos iminentes movimentos de recomposição dos agentes do poder, quais poderiam ser as alternativas sociais e políticas que esbocem cenários diferentes da barbárie e do colapso? Por um lado, grande parte da esquerda política, enraizada em posições socialdemocratas ou com matizes "progressistas", propõe uma espécie de Estado social, que ponha os trabalhadores e a justiça distributiva no centro. Por outro, uma esquerda mais social, que tende a desconfiar do Estado por razões teóricas e experiências histórico-práticas, sugere que o eixo central da resistência e da construção alternativa deve ser os territórios, a re-comunalização da vida social e as experiências anticapitalistas.

No primeiro caso, a ênfase está nos direitos, na defesa do público (no momento da pandemia, principalmente a saúde) e em uma escala nacional diante de um imaginário de enfrentamento à "crise sanitária” e suas consequências. Enquanto isso, no segundo caso prevalece a defesa do comum, do fortalecimento dos laços sociais no nível micro e da urgência de lutar por alternativas concretas em uma escala local diante de um imaginário que transborda o âmbito sanitário para entrar no enfrentamento à crise socioecológica e civilizatória. Não são necessariamente posições excludentes, senão que podem também se embricar, tensionar e retroalimentar. Muito além de caricaturas 
simplistas que muitas vezes se construíram sobre as "duas esquerdas", indicam caminhos diferentes frente aos sentidos de urgência, além de escalas políticas e imaginários geopolíticos bastante diferenciados.

Com este pano de fundo em mente, este artigo discute como a pandemia está afetando as recomposições da geopolítica do poder e das resistências, dedicando-se especialmente à política de escalas subjacente às mudanças que estamos experimentando. Após este panorama geral, a seção a seguir discute as características mais macro da reconfiguração geopolítica derivada da pandemia, enfatizando os âmbitos global e regional. Em seguida, o foco recai nas respostas e alternativas à crise nas escalas nacional e local. Por fim, são discutidos três cenários geopolíticos principais que emergem com a crise sanitária mas se projetam além desta, derivados da recomposição dos atores, das escalas e dos projetos políticos em disputa no mundo contemporâneo.

\section{Representações geopolíticas da pandemia: caos global e reorganização regional}

Durante as primeiras semanas e meses da pandemia do novo coronavírus, os debates intelectuais e políticos oscilaram entre o corona-otimismo e o coronapessimismo. No primeiro caso, celebraram-se as renovadas demonstrações de solidariedade, a enésima morte do capitalismo, os aprendizados positivos que a vivência da pandemia poderia gerar (como viver melhor com menos ou a divisão mais equitativa do cuidado) e a rearticulação de iniciativas locais e sujeitos coletivos. Já no segundo, enfatizaram-se os efeitos mais deletérios da pandemia: o egoísmo e o utilitarismo, o maior controle social, as restrições à liberdade e a deterioração das condições de vida. De certa maneira, trata-se da percepção clássica de que a crise pode ser vista como uma oportunidade ou uma ameaça. Há argumentos sólidos de ambos os lados, mas é fundamental reconhecer o caráter profundamente contraditório deste momento histórico, em que a crise é melhor compreendida em sua acepção chinesa do Wei Ji (危机 ), isto é, perigo e oportunidade ao mesmo tempo. Acrescente-se a isso a dimensão de emergência: talvez não restem muitas "oportunidades" em uma chave global e civilizatória para uma mudança de rumo frente ao que González Reyes e Fernández Durán (2018) definiram como o "longo declínio" da civilização industrial. 
Uma crise multidimensional e de grande magnitude como a que vivemos pode agitar processos macro-históricos de mudança em direções diversas, que dependem sempre da capacidade e da imaginação dos atores sociais e políticos para realizá-los, mas também de sua sedimentação social e política. São também momentos privilegiados de reorganização espacial de nossas sociedades e de redefinição das escalas de ação política. Diante da emergência de acontecimentos críticos, o alcance e a extensão das escalas geográficas costumam redefinir-se. Isso está acontecendo agora.

Durante as últimas três décadas, muito se discutiu sobre a globalização e a imbricação de escalas em um mundo crescentemente interconectado, o que resultou em um rico debate crítico sobre as dimensões territoriais e relações dos lugares e as mediações espaciais (Brenner, 1999; Sheppard, 2002). Este mesmo debate insistiu que as escalas se conectam habitualmente de maneira hierarquizada (Herod e Wright, 2002), mas não se forjam de modo linear ou apenas de cima para baixo, a partir de imposições verticais, senão são socialmente construídas e resultado de intensos conflitos e negociações políticas entre atores e projetos.

Destes confrontamentos, frequentemente emergem territorialidades $\mathrm{e}$ imaginários em disputa e inflexões nas relações de poder e resistência. Ainda é muito cedo para identificar e analisar as fontes, as práticas e as representações geopolíticas da "ordem mundial pós-coronavírus". Contudo, o momento inicial de expansão e de tentativas de controle da pandemia durante a primeira metade de 2020 é fundamental para decifrar os "movimentos geopolíticos" em suas aberturas, ativações e intencionalidades, ou seja, em plenos desdobramentos de recomposição da correlação de forças.

Poderíamos definir o momento atual como sendo de caos global. 0 caos não implica a ausência total de algum tipo de ordem, mas evoca a turbulência, a fragilidade e a indefinição geopolítica contemporânea diante dos múltiplos "riscos globais" e destinos possíveis (Prigogine e Stengers, 1997). A imprevisibilidade e a instabilidade passam a ser a regra e isso se refere não apenas à maior volatilidade frente às ameaças, mas também à própria dinâmica das forças políticas e do capitalismo contemporâneo. A ordem mundial que emergiu com a queda do Muro de Berlim buscou estender a democracia formal no mundo (por mais que as principais potências a desestabilizassem e interrompessem sempre que necessário) de mãos dadas com a globalização neoliberal, 
em uma espécie de "social-liberalismo global" (Domingues, 2013). Embora a democracia seja incompatível com o capitalismo (Wood, 2000), criou-se uma narrativa global de "prosperidade" e "estabilidade" mundial que confinava a democracia ao capitalismo. Esta estratégia está hoje sob suspeita diante das apostas de que o mercado internacional possa continuar mantendo-se bem, inclusive com as derivas autoritárias, os neofascismos e as constantes violações de direitos individuais.

Juntamente com isso, o que Ramón Fernández Durán havia chamado ironicamente de "globalização feliz" (Fernández Durán, 2003) recebe um xeque-mate com esta pandemia, após xeques anteriores, como o da crise de 2008, de que o capitalismo conseguiu escapar muito bem. Não estamos, como argumentam posições precipitadas, diante do fim da globalização e da emergência da "desglobalização", embora possivelmente frente ao fim da globalização capitalista as we know it. 0 grau de radicalização da expansão territorial e financeira do capital durante as últimas décadas foi possibilitado pela construção de um grande acordo capitaneado pelo Ocidente - com os Estados Unidos à frente (por mais que sua hegemonia esteja cada vez menor) -, que permitiu construir uma narrativa dominante de crescimento, sintonizada com a expansão ilimitada das empresas transnacionais e com o beneplácito de diversos grupos de poder e de organizações nacionais e internacionais. Seu desdobramento se deu, como se sabe, sob a remoção de qualquer tipo de barreiras diante de uma gramática de desregulação, flexibilização e liberalização que afiançou o neoliberalismo no mundo, ao mesmo tempo em que destruía o meio ambiente e o tecido social. Junto a isso, veio um processo de disputa cultural para enraizar a globalização neoliberal como um modelo não apenas econômico, mas também societal. Apesar das críticas ferozes do movimento anti/alterglobalização e de uma diversidade de resistências territoriais - e por mais que a crise de 2008 tenha destapado a dimensão mais trágica e letal do capitalismo financeiro e da globalização -, a resposta não foi uma alternativa a isso, mas uma radicalização do modelo. As perdas foram socializadas com toda a população e os Estados aplicaram políticas de ajuste e austeridade, enquanto salvavam os bancos, que, por sua vez, privatizaram os benefícios. A globalização capitalista pode, assim, seguir seu curso de acumulação e espoliação, aprofundando o modelo extrativista.

O cenário recente, amplificado em tempos de pandemia, parece ser diferente: entre diferentes setores da direita e da extrema direita, posições "anti-globalistas" e 
nacionalistas emergem em toda parte, seja no coração do sistema, nas "potências emergentes", ou em países periféricos, tratando de reorganizar o capitalismo de maneira mais fechada e autoritária. Por sua vez, o comércio internacional, as privatizações e os fluxos de capitais podem tropeçar com mais regulações públicas e políticas protecionistas propostas por atores diversos. Enquanto isso, a dependência de insumos e produtos de outros países (visível na pandemia com as máscaras ou os respiradores, mas cuja realidade se estende, em muitos casos, a produtos essenciais), está levando muitos países a revisarem suas políticas no futuro, pensando na autossuficiência ou na redução da dependência, como a China já faz há alguns anos. As estratégias de especialização e de internacionalização da produção, por outro lado, estão se reelaborando e os Estados centrais e as empresas transnacionais estão se reorganizando, com investimentos crescentes em tecnologias como a robotização ou a inteligência artificial.

O mundo, portanto, parece caminhar rumo a uma globalização capitalista mais descentralizada, reticular e ultra-tecnológica. As cadeias globais de valor serão mais frágeis diante da recessão pós-pandêmica e, embora não desaparecerão, tenderão a se reorientar. $\mathrm{O}$ arcabouço institucional supranacional projetado para facilitar as lógicas de acumulação pode perder peso diante de uma trama econômica e política mais complexa de acumulação nas cidades e em redes hierárquicas, muitas das quais apostarão mais na relocalização parcial da produção.

Cabe insistir em que nem tudo é novo, mas a pandemia pode acelerar e consolidar mudanças geopolíticas que já vinham se precipitando durante a última década. É o caso do fortalecimento da China, que, mesmo que não se torne um novo hegemon no curto prazo, terá um papel cada vez mais decisivo no sistema mundial, com consequências que vão além do âmbito econômico e que ainda precisam ser melhor analisadas em sua totalidade. A brecha entre centro e periferia, por outro lado, tende a aumentar ainda mais, devido tanto à centralidade do desenvolvimento tecnológico quanto à recessão econômica, que costumou ser acompanhada de um receituário macroeconômico conhecido e nefasto para os países do Sul.

Estes cenários e tendências reforçam que a ordem geopolítica vigente estará previsivelmente marcada por uma maior rivalidade no sistema interestatal, desconfiança entre atores políticos e econômicos, mas também pelo aprofundamento, 
por parte dos atores dominantes, da militarização global (Cairo, 2018), que poderá fortalecer o caos sistêmico. Parece difícil que uma nova governança global da saúde possa emergir, tanto pelo papel vacilante da Organização Mundial da Saúde (OMS) quanto pela própria falta de comprometimento dos Estados. As organizações internacionais e multilaterais de todo tipo também não estiveram à altura da tragédia da pandemia, seja por silêncio, incapacidade ou incongruência.

A maioria dos blocos regionais, por sua vez, saem fragilizados e, em alguns casos, desmantelados e sem autoridade moral diante da pandemia. É o caso da União Européia que, durante a crise sanitária global, perdeu a oportunidade de estabelecer-se como uma alternativa ao fracasso da resposta à pandemia dos Estados Unidos, mas também frente ao modelo centralizado e autoritário chinês. As fissuras e as assimetrias dentro do bloco voltaram a aparecer, dificultando a coordenação interna e a projeção externa. Por sua vez, aqueles projetos regionais que há alguns anos tentavam projetar-se na América Latina como regionalismos contra-hegemônicos - como a União de Nações SulAmericanas (UNASUL), a Comunidade de Estados Latino-americanos e Caribenhos (CELAC) e a Aliança Bolivariana para os Povos da Nossa América - Tratado de Comércio dos Povos (ALBA-TCP) (Cairo, Bringel e Ríos, 2019) - passaram quase despercebidos na pandemia e não tiveram envergadura suficiente para construir qualquer resposta política supranacional relativamente bem articulada. Os BRICS, outra iniciativa criada com pretensões contra-hegemônicas - embora nunca anti-sistêmicas -acordaram, no final de abril de 2020, apesar do governo Bolsonaro e das tensões entre a diplomacia do Brasil e da China, avançar na cooperação para minimizar os efeitos da pandemia.

Porém, curiosamente, foi o Fórum de Cooperação Econômica Ásia-Pacífico (APEC), criado no simbólico ano de 1989 para promover o livre comércio na região, aquele que respondeu de maneira mais enfática propondo a cooperação regional como chave para o enfrentamento da pandemia. Isso incluiu a coordenação e o intercâmbio, entre os 21 países membros, de informações e produtos, bem como ajudas econômicas de financiamento frente à emergência (Hernando e Andrés, 2020). A discussão, neste caso, sobre a centralidade da cooperação na região no cenário pós-pandemia está orientada pelo objetivo de coordenar políticas de estímulo ao comércio e aos negócios.

Definitivamente, os projetos regionais e inter-regionais não foram os principais protagonistas da pandemia. Em alguns casos, a pandemia pode presumir o enterro 
definitivo de alguns projetos regionais, a menos que se reinventem profundamente. É o caso da UNASUL frente à recente criação do Foro para o Progresso da América do Sul (PROSUL), impulsionado por governos neoconservadores. Em outros, o regionalismo tenderá a se reorganizar em função das mudanças geopolíticas e geoeconômicas mais amplas. 0 eixo do Pacífico ganha mais centralidade, mas é necessário acompanhar de perto iniciativas mais amplas e de grande envergadura, como a Belt and Road Initiative lançada pelo governo chinês. Também resta saber se poderão surgir novos projetos inter-regionais criativos e críticos que respondam aos desafios planetários ou se os rearranjos servirão, como é habitual, para que os regionalismos acabem servindo como meras correias de transmissão do capitalismo.

\section{Entre a contenção do vírus e a contestação social: choque nacional e alternativas locais}

A globalização neoliberal, as múltiplas dinâmicas de transnacionalização e os processos de regionalização teriam levado, segundo muitos autores, ao debilitamento ou à crise terminal dos Estados-nação, conforme a ênfase de cada um. É certo que o papel dos Estados mudou nas últimas décadas e que estes foram desafiados a partir de dentro e de fora de suas fronteiras, contudo, continuam sendo os atores políticos hegemônicos no mundo.

Durante a pandemia, os sentimentos nacionais foram massivamente mobilizados e o Estado interventor foi reivindicado até pelos neoliberais. Uma espécie de "Leviatã sanitário transitório" emergiu, como propõe Svampa (2020). Com ele vieram, em boa parte dos casos, as políticas de proteção social e sanitária, mas também os militares nas ruas, estados de emergência nos quais tudo se suspende e a instalação de uma perigosa narrativa bélica. E acontece que a vigilância permanente - das formas mais clássicas aos rastreamentos digitais e drones -, o controle e o gerenciamento de big data, os novos dispositivos de reconhecimento facial e outras formas sofisticadas de controle social não estão se aprofundando apenas para combater um vírus. Medidas de concentração de poder adotadas para combater a Covid-19 podem inclusive ser necessárias para possibilitar o atendimento público da saúde e a "proteção" da população. Todavia, existe uma fronteira muito tênue entre isso e as práticas autoritárias (Bringel, 2020). 
As respostas estatais foram diversas, variando também de acordo com os perfis dos regimes políticos. Em alguns casos, prevaleceu um capitalismo de Estado autoritário, enquanto em outros a face mais social do Estado apareceu. No entanto, boa parte das análises sobre a gestão estatal da crise procurou sublinhar (sempre com uma forte carga normativa) os casos de "êxito" e de "fracasso". A variável principal, para isso, foi a contenção dos casos de contagiados e de mortos. Certamente podem existir estratégias mais bem-sucedidas do que outras e casos em que o negacionismo, unido à incompetência (nisso é difícil ganhar de Bolsonaro e Trump), oferece o pior lado das respostas ofertadas. Contudo, não podemos esquecer que, no caso dos Estados dependentes da periferia e da semiperiferia mundial, as dificuldades para enfrentar a pandemia são ainda maiores: sistemas de saúde pública praticamente inexistentes, minado direito à água, casas precárias e ultrapovoadas nas periferias urbanas e limitadas capacidades estatais.

Não obstante, a importância do Estado e do nacional coexistiu com uma forte revalorização dos lugares e da escala local. Em todo o mundo, proliferaram iniciativas locais que trataram de gerar dinâmicas de apoio mútuo e de construir bairro e comunidade com o objetivo de dar respostas coletivas a partir de baixo, com base nas necessidades cotidianas das pessoas. Frente à impossibilidade de protestar nas ruas, boa parte das análises sobre as resistências em tempos de coronavírus tendeu a enfatizar o papel fundamental do ativismo digital, mas também a criatividade dos movimentos sociais para gerar espaços e propostas inovadoras (Della Porta, 2020). A imprensa, como de costume, olhou apenas para a parte mais visível das ações cidadãs e dos movimentos sociais, como os flash mobs, os panelaços ou as petições eletrônicas. Embora esta tenha sido uma parte importante das ações de contestação durante a pandemia, é fundamental observar também o que se move por baixo da superfície do visível, como a autoorganização e a proteção dos trabalhadores que tiveram que continuar trabalhando, seja por questões de sobrevivência, seja porque suas tarefas se enquadram no que são considerados "serviços essenciais" (Wood, 2020).

Para além das necessidades materiais e do imediato, a aposta de muitos grupos e coletividades pelo comunitário e pela reconstrução do vínculo social em tempos de profunda individualização da sociedade tem sido uma das características mais significativas. Buscou-se, também, visibilizar a desigualdade na divisão dos cuidados, a 
solidariedade e a soberania alimentar e energética. 0 confinamento de $1 / 3$ da população mundial serviu, da mesma forma, para difundir uma mensagem em que as feministas insistem há muito tempo: o corpo também deve ser considerado como uma escala.

A escala local não foi importante apenas em um sentido transformador não institucional e, em alguns casos, anti-institucional. Nos países que não conseguiram impulsionar medidas contundentes para todo o território nacional, houve uma forte queda de braço com líderes locais e regionais que, juntamente com as iniciativas extraoficiais, assumiram o protagonismo institucional do combate à pandemia. Em outros casos, municípios progressistas também procuraram impulsionar e promover plataformas colaborativas de cuidado ou assumiram diretamente as rédeas da gestão da crise.

Este "novo retorno" dos lugares e sua centralidade para as resistências sociais e os movimentos sociais em tempos de coronavírus não podem nos levar a recair em dicotomias que pareciam já superadas, mas que voltam a circular amplamente hoje, como que a escala global é o lugar do capitalismo e a escala local o locus das resistências. Conforme insisti em várias ocasiões (Bringel, 2015), nas últimas duas décadas as lutas sociais localizadas foram as mais globalizadas ou, caso se prefira, os movimentos territorializados são os que mais conseguiram se internacionalizar. Isso foi assim, por exemplo, para os movimentos camponeses e indígenas desde os anos 1990, mas também para as diversas experiências reunidas em torno do movimento alterglobalização e de justiça global e ambiental. No entanto, a emergência do que defini como uma nova "geopolítica da indignação global", durante a última década, parece ter levado a uma menor intensidade de densidade organizacional entre as lutas sociais no mundo.

Que o protesto se espanda globalmente, ou melhor, por diferentes países do mundo, não significa que esteja necessariamente se globalizando em um sentido forte, isto é, que esteja se articulando com laços sólidos e construindo uma resposta realmente global ao sistema-mundo capitalista. Por um lado, é necessário distinguir entre ações globais e movimentos globais. Por outro, diante da explicação de Billion e Ventura (2020) de que estaríamos frente a novas culturas políticas sem tanto afinco internacionalista, seria preciso aprofundar mais o debate sobre as mudanças na "formamovimento" e nas modalidades de ativismos hoje no mundo que, embora sigam coexistindo com formatos mais tradicionais, nos obrigam a questionar lentes prévias 
para captar deslocamentos cognitivos, geracionais e identitários, com importantes repercussões sobre as práticas de resistência, as articulações políticas e as concepções e os horizontes de transformação social.

\section{Cenários geopolíticos depois da crise sanitária: recuperação, adaptação ou transição}

Com o achatamento da curva, a imunização de boa parte da população ou a descoberta da vacina e um mínimo controle da pandemia da Covid-19, parece difícil acreditar que entraremos em um cenário de pactos globais inovadores. Por que pensar que, no sistema interestatal capitalista, a cooperação e a solidariedade prevaleceriam agora? Em princípio, apesar das resistências que possam surgir, o caos global tende a aprofundar-se, mas os novos vetores não se dão de forma abstrata, senão a partir de projetos políticos enfrentados que adquirem novos sentidos a partir da pandemia.

Ainda que na geopolítica clássica tenha havido um forte "geodeterminismo" no sentido da disposição das ações políticas às condições ambientais ou dos lugares (O'Loughlin, 1994; Flint, 2006), o antropocentrismo predominante na modernidade permitiu que a expansão territorial e a acumulação do capital não tivessem limites, desde que o homem conseguisse "domesticar" a natureza e os recursos naturais. Embora os limites ecossistêmicos já tenham sido ultrapassados há tempos, a pandemia parece abrir uma inflexão no que se refere à centralidade que adquirem o meio ambiente e os cenários geopolíticos possíveis vis-à-vis os modelos sociais e econômicos.

No debate político contemporâneo, três projetos diferentes disputam os rumos do mundo pós-pandemia: o business as usual, centrado no crescimento do PIB, no desenvolvimentismo e na busca por novos nichos de mercado para sair da crise, a partir de políticas de ajuste que exigem, mais uma vez, o sacrifício de todos para maximizar o benefício e o lucro de alguns poucos; o "Green New Deal”, que embora surja inicialmente nos Estados Unidos, como proposta institucional de deputados democratas para gerar profundas reformas sociais e econômicas que levariam a uma transformação do sistema energético, se difunde muito rapidamente no último ano (e muito especialmente durante o pandemia), com apropriações diversas de empresas, organizações internacionais e da própria União Europeia, que está criando seu próprio "European Green Deal”; e, 
finalmente, a mudança de paradigma em direção a uma nova matriz econômica e ecossocial, proposta por movimentos ecologistas mais combativos e diversos setores anticapitalistas que apostam pelo decrescimento e medidas mais disruptivas como a única alternativa possível 5 .

Estes projetos parecem nos levar a três cenários possíveis, que não ocorrem de forma "pura" e podem embricar-se de múltiplas maneiras, embora todos tenham sua lógica própria: a recuperação da lógica mais agressiva do crescimento econômico; a adaptação do capitalismo a um modelo "mais limpo", embora socialmente desigual; ou a transição para um novo modelo, que implique uma nova matriz ecossocial e econômica. Diante destes projetos e cenários, é importante nos perguntarmos sobre as implicações de cada um deles. A implementação do "business as usual" suporia um fortalecimento ainda maior da globalização militarizada, da biopolítica do neoliberalismo autoritário e de um modelo de espoliação destrutivo que levaria, previsivelmente, a cenários ainda mais catastróficos, entre os quais se incluem guerras e o aprofundamento da crise ecossocial. 0 "retorno à normalidade" ou mesmo "a nova normalidade" são discursos que justificam e asseguram este tipo de cenário.

No caso da adaptação a um capitalismo verde, se prevêem reajustes geopolíticos e geoeconômicos profundos. Segundo esta visão, já não é suficiente somente uma maquiagem verde, que começou com a Cúpula da Terra de 1992 no Rio de Janeiro e com a “adjetivação" do desenvolvimento como "sustentável” (Bringel e Echart, 2017). Agora, seria necessário dar um passo além. E sabemos que, se o capitalismo aceita dá-lo, não o faz necessariamente pelo meio ambiente, mas porque este pode ser uma via para maximizar os lucros. As novas estratégias de coexistência entre a acumulação do capital com o imaginário ambientalista poderão dar mais margem de autonomia à política local, mas poderiam aprofundar as desigualdades Norte/Sul e o racismo ambiental.

No entanto, é necessário ser justo: este cenário predominantemente "adaptativo" ainda está em forte disputa. Por um lado, parte importante das coletividades dominantes, principalmente no Ocidente, entende que é um caminho a se seguir. Por outro, forças políticas que defendem a justiça social e a sustentabilidade buscam

\footnotetext{
${ }^{5}$ Embora estes cenários sejam contemplados em uma multiplicidade de leituras, nem sempre são feitos em sua complexidade, salvo algumas exceções, como o fantástico relatório elaborado pela equipe de Ecologistas en Acción que não apenas desenha de maneira muito pertinente os cenários possíveis diante da crise ecossocial, senão explora os limites e as possibilidades de cada um deles para o caso espanhol, com especial atenção ao lugar do emprego e do trabalho (González Reyes et al., 2019).
} 
tensioná-lo de várias maneiras, no sentido de uma ruptura e uma reconfiguração integral. É o caso de propostas que reivindicam, desde o Sul, a "descolonização" da lógica do Green New Deal; ou que dialogam criticamente com seus pressupostos, mas os aterrissam em outras realidades, como a latino-americana, dando mais centralidade ao Estado e às contribuições das lutas populares, com o objetivo de promover um grande pacto ecossocial e econômico (Svampa e Viale, 2020) que pode servir para algumas realidades nacionais e como base para imprescindíveis diálogos Norte/Sul.

Finalmente, o terceiro cenário é o mais difícil, mas também o mais necessário para que o meio ambiente não seja somente, once again, uma bandeira para salvar o capitalismo, senão para salvar a humanidade e o planeta. A transição rumo a uma mudança radical de matriz ecossocial não se fará apenas pela via estatal, mas tampouco se fará sem ela. São os próprios movimentos sociais, as experiências territoriais e uma diversidade de lutas e frentes populares e político-intelectuais que poderão impulsionar este cenário, tensionando os limites das narrativas do capitalismo verde e dialogando criticamente com os governos e as institucionalidades mais sensíveis - ao mesmo tempo, buscando transformá-los. Para isso, não há uma receita, mas sim uma multiplicidade de estratégias de desvencilhamento da globalização capitalista e de articulação de uma nova globalização de lutas translocais. Muitas já estão em andamento e buscam reinventar as solidariedades transnacionais e o internacionalismo militante.

Neste caso, parece voltar, timidamente, mas com ares renovados, o debate geopolítico sobre a "desconexão", muito importante em várias posições terceiromundistas e sistematizado por Amin (1988). Para o autor, a desconexão não seria sinônimo de "recolhimento autárquico" ou de isolamento, senão um manejo ativo e crítico das relações da sociedade nacional com o exterior, seguindo as prioridades para seu "desenvolvimento interno". A principal diferença entre a formulação de Amin e as propostas contemporâneas que seguem uma linha similar é que o autor egípcio ainda pensava principalmente em termos de países e sociedades nacionais, dentro de um esquema clássico de polarização centro-periferia, por mais que considerasse os limites das relações entre as economias periféricas para a superação do imperialismo e para a articulação de um internacionalismo realmente combativo, que mobilizasse a classe trabalhadora, a solidariedade e o internacionalismo dos povos. 
$\mathrm{Na}$ atualidade, estamos frente a iniciativas de desconexão que deslocam e transbordam as unidades "nação", "economias nacionais" e "Estado" para dar centralidade às localidades, aos territórios e às experiências localizadas. Samir Amin, afinal, era um internacionalista e sua proposta sobre a desconexão, embora anticapitalista, não era a "saída" do mundo moderno. Ao contrário, sua disputa centravase na valorização da autonomia e no horizonte de construção do socialismo. 0 eixo de gravitação da proposta partia do marxismo e ancorava-se no eixo afro-asiático, com fortes polêmicas sobre o eurocentrismo e não apenas a importância, mas também as dificuldades na articulação das lutas populares do Sul Global entre si e com as iniciativas sociais do Norte (Teivainen, 2019). As propostas de "desconexão" emergentes na atualidade são na verdade nucleadas ao redor do autonomismo e do ecologismo social, com uma força especial na América Latina e em algumas coletividades europeias, embora também sigam vivas no continente africano.

Hoje, avançar nesta direção exigirá sacrifícios e mudanças drásticas que vão do âmbito pessoal (mudança de hábitos, redução do consumo ou diminuição de viagens) ao mais macro (políticas que possibilitem a relocalização dos alimentos e uma mudança no sistema alimentar ou o decrescimento radical em setores como o petróleo, o gás e a mineração), passando também pelas relações trabalhistas e pela vida social como um todo. Também implica resistir territorialmente buscando novas formas de articulação, conexão e inteligibilidade dentro do mapa global de lutas emergentes. Somente assim poderemos passar de uma globalização destrutiva para um "pluriverso" (Kothari et al., 2019). Somente assim outros mundos possíveis poderão emergir.

\section{Referências}

AMIN, S. (1988) La Desconexión: hacia un sistema mundial policéntrico. Madrid: IEPALA.

BILLION, D. y VENTURA, C. (2020) “¿Por qué protesta tanta gente a la vez?, Revista Nueva Sociedad, n.286, p.37-52.

BRENNER, N. (1999) "Beyond State-centrism? Space, Territoriality, and Geographical Scale in Globalization Studies", Theory and Society, v.28, n.1, pp.39-78.

BRINGEL, B. (2020) "Mucho más que un cacerolazo: resistencias sociales en tiempos de Covid-19”, Open Democracy, 3 de abril de 2020. 
BRINGEL, B. (2015) "Social movements and contemporary modernity: internationalism and patterns of global contestation". In: Breno Bringel y José Maurício Domingues (Eds.) Global Modernity and Social Contestation. Londres/California/New Delhi: SAGE, 2015, p.122-138.

BRINGEL, B. y ECHART, E. (2017) “Imaginarios del desarrollo en América Latina: entre la emancipación y la adaptación al capitalismo”, Revista Española de Desarrollo y Cooperación, v.39, p.9-24.

CAIRO, H. (2018) Las guerras virtuosas de George W. Bush: las transformaciones del territorio, de la soberanía y de los discursos geopolíticos en el siglo XXI. Madrid: Trama Editorial.

CAIRO, H.; BRINGEL, B.; SIERRA, J. (2019) “Geopolítica externa del regionalismo latinoamericano: nuevas configuraciones en el orden mundial contemporáneo", Controversias y Concurrencias Latinoamericanas, 11(19), p.77-99.

DELLA PORTA, D. (2020) "Movimientos sociales en tiempos de Covid-19: otro mundo es necesario", Open Democracy, 26 de marzo de 2020.

DOMINGUES, J. M. (2013) “Social liberalismo y dominación global”, Geopolítica(s), vol.4, n.2, p.183-198.

FERNÁNDEZ DURÁN, R. (2003) Capitalismo financiero (global) y guerra permanente. Barcelona: Virus.

FERNÁNDEZ DURÁN, R. y González Reyes, L. (2018) En la espiral de la energía (vol. II): Colapso del capitalismo global y civilizatorio. Madrid: Ecologistas en Acción / Baladre.

FIDLER, D. (2020) “Coronavirus: A Twenty Years Failure”, Think Global Health, 23 de marzo de 2020.

GONZÁLEZ REYES, L. et al. (2019) Escenarios de trabajo en la transición ecosocial 20202030. Madrid: Ecologistas en Acción.

HEROD, A. y Wright, M. W. (2002) Geographies of Power: placing scale. Oxford: Blackwell Publishers.

HERNANDO, R. y ANDRES, E. (2020) “APEC in the Epicentre of Covid-19”, APEC Policy Support Unit, Policy Brief, n.31, abril de 2020.

HERRERO, Y. (2006) "El movimiento ecologista ante el deterioro global: retos y utopías", Intervención Psicosocial, v.15, n.2, p.149-166.

KHOTARI, A.; SALLEH, A.; ESCOBAR, A.; DEMARIA, F. y ACOSTA, A. (2019) Pluriverso: un diccionario del posdesarrollo. Barcelona: Icaria.

MACAMO, E. (2020) "The normality of risk: African and European responses to Covid19", Blog Corona Times, HUMA - The Institute for the Humanities in Africa, 13 de abril de 2020. 
O’LOUGHIN, J, (ed.) (1994) Dictionary of Geopolitics. Westport: Greenwood Press.

PRIGOGINE, I.; STENGERS. I. (1997) The end of certainty: time, chaos, and the new laws of nature. New York: First Free Press.

RAMONET, I. (2020) "Ante lo desconocido... la pandemia y el sistema-mundo", Le Monde Diplomatique, edición chilena, 30 de abril de 2020.

SEGATO, R. (2020) "Todos somos mortales: del significante vacío a la naturaleza abierta de la historia”, Lobo Suelto, 19 de abril de 2020.

SHEPPARD. E. (2002) "The Spaces and Times of Globalization: places, scales, networks, and positionality", Economic Geography, v.78, n.3, pp.307-330.

SVAMPA, M. (2020) "Reflexiones para un mundo post-coronavirus”, Revista Nueva Sociedad, abril 2020.

SVAMPA, M; VIALE, E. (2020) “Justicial ecosocial y económica: nuestro Green New Deal”, Revista Anfibia, Universidad Nacional de San Martín.

TEIVAINEN, T. (2019) "Eurocentrism, state-centrism and sexual self-determination in the construction of a global democratic organization", Globalizations, v.16, n.7, p.11021108.

WOOD, E. (2000) Democracia contra capitalismo: la renovación del materialismo histórico. México D.F.: Siglo XXI.

WO0D, L. (2020) "Social movements as essential services", Open Democracy, 30 de abril de 2020. 